\title{
Why Do Employees Have Better Family Lives When They Are Highly Engaged at Work?
}

\author{
Remus Ilies \\ National University of Singapore \\ Xiao-Yu Liu \\ University of International Business and Economics \\ Yukun Liu \\ National University of Singapore
}

\author{
Xiaoming Zheng \\ Tsinghua University
}

Acknowledgements: Xiao-Yu Liu and Yukun Liu contributed equally to the development of this article. This work was supported by the National Natural Science Foundation of China (grant numbers 71372005, 71672036, 71272022).

Correspondence concerning this article should be addressed to Xiaoming Zheng, Department of Leadership and Organization Management, School of Economics and Management, Tsinghua University, Beijing 100084, P. R. China, or to Xiao-Yu Liu, Department of Human Resource Management and Organizational Behavior, Business School, University of International Business and Economics, Beijing 100029, P. R. China. E-mail: zhengxm@sem.tsinghua.edu.cn or liuxy@uibe.edu.cn. 
Running Head: WORK ENGAGEMENT AND FAMILY LIFE

Why Do Employees Have Better Family Lives When They Are Highly Engaged at Work? 


\begin{abstract}
Past research on the effects of work engagement on the family has demonstrated contrasting effects, with some suggesting that work engagement is beneficial for family life while others suggesting that it may be detrimental. In the present research, using a sample of 125 employees who responded to daily surveys both at work and at home for two consecutive weeks, we present a multilevel examination of the relationships of work engagement to family outcomes aimed at elucidating such work-family effects. Our findings revealed that employees' daily work engagement experiences related positively, within individuals, to work-family interpersonal capitalization, which in turn, related positively to daily family satisfaction and to daily workfamily balance. Our findings also indicate that both the relationship between daily work engagement and work-family interpersonal capitalization and the indirect effects of daily work engagement on the family outcomes were stronger for employees with higher intrinsic motivation than for those with lower intrinsic motivation. We discuss theoretical and practical implications of our findings and offer directions for future research.
\end{abstract}

Keywords: $\quad$ work engagement, work-family interpersonal capitalization, family satisfaction, work-family balance 
For most people, work and family represent important roles in which they participate for the majority of their adult life, and these two life roles are inextricably linked through several mechanisms. For example, work provides one with the material resources necessary for fulfilling family obligations (e.g., paying rent or mortgage) or achieving family-related goals (e.g., sending children to college). However, participating in the work role can deplete one's resources such that he or she is not able to fulfill his or her family responsibilities adequately, thus creating work-family conflict. The process by which work conflicts with family usually starts with high job demands which require an excessive amount of resources, be those physical, cognitive or emotional. Under this scenario, in the absence of alternative (replacement) resources and without recovery of the depleted ones, the employee cannot perform his or her family role adequately because he or she lacks the necessary resources, and this inadequate performance decreases the quality of his or her family life. Yet work can also be fulfilling, engaging, enriching and energizing, and therefore a different work-family linkage mechanism may exist (besides resource depletion) by which participating in the work role can make family life better.

This paper focuses on examining whether work engagement, "a positive, fulfilling, work-related state of mind that is characterized by vigor, dedication, and absorption" (Schaufeli, Salanova, González-Romá, \& Bakker, 2002, p. 74), translates into higher-quality family life and, if yes, why would work engagement result in a better family life. Although understanding how excessive job demands or work stressors translate into lower-quality family life, and what can be done to diminish such effects, is certainly important as it informs potential interventions, focusing on the positive side of work and its potential beneficial effects for family life is equally important yet it has been seldom studied (e.g., Grzywacz, Carlson, Kacmar, \& Wayne, 2007; Ilies, Keeney, \& Scott, 2011). If our general hypothesis that work engagement leads to higher-quality family life - is true, organizations would stand 
to gain by designing work that is conducive to the experience of work engagement for employees, through increased productivity, and employees would have their own benefits, in terms of both the economic (material) rewards associated with increased productivity and the psychological benefits stemming from having higher family satisfaction and better workfamily balance.

As we alluded to above, we study the positive side of the work-family interface, following numerous calls in the literature for an expansion of the work-family paradigm beyond work-family conflict (e.g., Greenhaus \& Powell, 2006; Grzywacz et al., 2007; Siu et al., 2010). Thus, we position our work within the literature on work-family facilitation (or enrichment; Rothbard, 2001), which refers to the extent to which one's engagement in the work domain provides gains that contribute to enhanced functioning in the family domain (e.g., Wayne, Grzywacz, Carlson, \& Kacmar, 2007). ${ }^{1}$ Given that, as an experiential state of mind, work engagement represents “employees' experience of work activity, and not the predictors or outcomes of these experiences" (Bakker \& Leiter, 2010, p. 182), we propose that work engagement represents the start of a process of work-family facilitation that has the end outcome a high-quality family life. More specifically, to assess the quality of employees' family lives, we focus on family satisfaction, which reflects one's attitude about one's family (similar to job satisfaction reflecting one's attitude about one's job) as studied by Kopelman, Greenhaus, and Connolly (1983), and on work-family balance, which refers to the effective accomplishment of socially negotiated role responsibilities in the work and family roles by employees (see Carlson, Grzywacz, \& Zivnuska, 2009).

Furthermore, following recent theorizing and research on the concept of work-family interpersonal capitalization, defined by Ilies et al. (2011, p. 116) as "discussing positive work events and experiences with one's spouse or partner at home" (see also Culbertson, Mills, \&

\footnotetext{
${ }^{1}$ Recognizing the bidirectional nature of work-family facilitation (e.g., Wayne et al., 2007) we note here that we actually study a process of work-to-family facilitation.
} 
Fullagar, 2012, and Ilies, Keeney, \& Goh, 2015), we propose and test a mediated model by which work engagement, as an experiential state, leads to a more satisfying family life and to higher work-family balance because it stimulates work-family interpersonal capitalization which in turn affects the family outcomes.

\section{Intended Contribution}

We first aim to contribute to the broader literature on the consequences of work engagement for employees' family lives. Herein, we adopt the conceptualization of work engagement as defined by Bakker, Schaufeli and their colleagues as a positive experiential state characterized by vigor, dedication and absorption (e.g., Bakker, Albrecht, \& Leiter, 2011; Schaufeli \& Bakker, 2010). With respect to employees' family lives, there is currently a debate in the literature about the outcomes of work engagement, with several scholars suggesting that work engagement depletes resources and thus might result in work-family conflict (e.g., George, 2011; Halbesleben, Harvey, \& Bolino, 2009) whereas others proposing that work engagement is beneficial for family life (e.g., Culbertson et al., 2012; RodríguezMuñoz, Sanz-Vergel, Demerouti, \& Bakker, 2014). In our study, we conceptualize work engagement at the daily level and we study its effects on family life dynamically as these effects unfold from one day to another (see Bakker et al., 2011; Sonnentag, 2011; Xanthopoulou, Bakker, Demerouti, \& Schaufeli, 2009a). We take this approach because we believe that the difference in the levels of conceptualization (and analysis) of the process by which work engagement affects family life (i.e., between- vs. within-individuals) might explain previous divergent results (e.g., Halbesleben et al., 2009; Rodríguez-Muñoz et al., 2014).

In our view, dynamic daily studies examining within-individual relationships are best positioned to reveal whether or when work engagement has positive effects on family life, and this is one of our objectives with the research presented herein, anchored within the 
discussion on the costs and benefits of work engagement for employees (George, 2011). That is, estimating the within-individual relationship, from day to day, among work engagement and the quality of family life, implies linking deviations (or changes) in employees' daily engagement relative to their average level of engagement with similar deviations (or changes) in the quality of family life, and therefore the within-individual estimate is free of personbased biases (e.g., social desirability, rating tendencies, personality effects, etc.) and retrospective bias is also minimized (Reis \& Gable, 2000).

Even though the literature on applied psychology and organizational behavior has seen an increase in the volume of within-individual research on employee well-being (see Ilies, Aw, \& Pluut, 2015) and on work and family (see Butler, Song, \& Ilies, 2013), not much is understood about how work engagement affects people beyond work on a day-to-day basis. To be sure, there has been within-individual research on work engagement (see Bakker, 2014) and also some research on various outcomes of work engagement (e.g., weekly self-rated job performance, Bakker \& Bal, 2010; recovery level at the end of the workday, Sonnentag, Mojza, Demerouti, \& Bakker, 2012; day-level financial returns, Xanthopoulou, Bakker, Demerouti, \& Schaufeli, 2009b). However, we found only two within-individual studies that examined the effects of work engagement on employees outside work: Culbertson et al. (2012), who examined the within-individual relationship between work engagement and work-family facilitation, and Rodríguez-Muñoz et al. (2014), who examined the withinindividual relationship between daily work engagement and daily happiness.

Second, we seek to contribute to the work-family facilitation or enrichment literature by uncovering a behavioral process by which work can enhance family life. Ilies et al. (2011, p. 124) found that employees' job and marital satisfaction were more strongly related on days when work-family interpersonal capitalization occurred (see their additional analyses) and interpreted this result as reinforcing "the idea that work-family interpersonal capitalization is 
a potential mechanism through which work-family enrichment occurs." Following this idea, and given the recent calls for the study of work-family processes within individuals (Butler et al., 2013), we propose and test a dynamic (daily, within individuals) model specifying workfamily capitalization as an explanatory behavioral action that links work engagement to satisfaction with family life and to work-family balance. We believe this contribution is timely and important, given the relative paucity of research on the positive influence of work on family (e.g., Wayne et al., 2007), and represents a contribution beyond that of Ilies et al. (2011) in that we propose and test an antecedent of work-family interpersonal capitalization. Third, inspired by George's (2011) discussion of the intrinsic vs. extrinsic benefits of work engagement, we propose that the personal benefits of high work engagement for employees are contingent on their own motivation for working, such that work engagement leads to positive outcomes especially when (or perhaps only when) employees are intrinsically motivated at work. As a particular case of this general proposition, we hypothesize and test interactive effects between work engagement and intrinsic motivation on work-family interpersonal capitalization, family satisfaction and work-family balance. Given that recently there have been calls for a re-examination of the purported benefits of high work engagement for employees (e.g., George, 2011), we believe it is timely to identify when these benefits are occurring (i.e., identify moderators) and thus we test intrinsic motivation as a qualifier for such beneficial effects.

To achieve these contributions, first, we develop hypotheses that represent formal statements of the relationships depicted in our conceptual model (see Figure 1). The hypotheses and the conceptual reasoning behind them are presented in the following section; in the remainder of the paper, we describe a multilevel study designed to test these hypotheses and its results, and we then discuss the implications of our theorizing and findings. 


\section{THEORY AND HYPOTHESES}

In building conceptual support for our model, we draw on the Work-Home Resources (W-HR) model (ten Brummelhuis \& Bakker, 2012). At the most general level, this model specifies that individuals have both demands and resources in their work and family domains; demands from the two roles compete for resources, whereas resources help in meeting demands and can also be accumulated. Following Hobfoll (2002), the W-HR model categorizes resources into two types along their source or origin: contextual resources, which originate from the outside of the self (e.g., from work), and personal resources, which reside inside of the self (e.g., personal traits or energies). Building upon this typology of resources, work-family enrichment is described in the W-HR model as a resource accumulation process: contextual resources derived from the work domain lead to the development of personal resources, and these personal resources, in turn, are utilized to enhance outcomes in the family domain.

As mentioned, work engagement is a positive experiential state characterized by vigor, dedication, and absorption (Schaufeli et al., 2002). Vigor refers to high levels of investment of energy and mental resilience while working. Dedication refers to meaningful experiences with significance, enthusiasm, inspiration, pride, and challenge involved. Absorption is characterized by being fully concentrated on one's work. We propose that the significance, meaningfulness and pride associated with work engagement (or that are part of the engagement experience) are all contextual resources, because they are associated with experiencing an activity at work, that lead to the accumulation of personal resources promoting work-family enrichment, thus having positive effects on family life, as suggested by the W-HR model. 
Using depletion and enrichment arguments that are consistent with the WH-R model, Rothbard (2001) proposed that engagement in the work role can have both positive and negative effects on engagement in the family role (through positive and negative emotions). Given that we use the Schaufeli, et al. (2002) conceptualization of work engagement as a positive state (i.e., Rothbard conceptualized engagement in the work role as more of a valence-free construct comprising of attention and absorption), we would expect work engagement to have mostly enriching effects on the family, likely increasing family engagement through positive emotions (such as pride) as Rothbard's enrichment path suggests. Then if the positive experience of work engagement translates into positive family experiences (such as family engagement) through the process of enrichment, it should also influence family outcomes positively, as also suggested by the WH-R model.

Being highly engaged at work should also make people feel more accomplished at work on that day, which enhances their general satisfaction with life, a subset of which is family satisfaction. With respect to work-family balance, it is likely that employees feel that they gave their best at work after a day when they were highly engaged (Kahn, 1990), and thus they can devote more attention to family life when at home, which increases their perceptions of work-family balance. Such a process is tentatively supported by the finding of Bakker, Petrou, and Tsaousis (2012) that work engagement was positively related to investment in the relationship with the partner, in a sample of teachers and their partners. The enrichment effect whereby high work engagement translates into high family engagement (Rothbard, 2001) also suggests that on days when work engagement is high, employees perceive higher work-family balance, because they were actually highly engaged both at work and at home and thus they feel they were effective in both their work and family roles.

As noted, these effects from work engagement to the family outcomes represent a work-family process by which work enriches family life by increasing satisfaction and 
balance. As noted, a similar work-family enrichment effect was demonstrated at a more general level by Culbertson et al. (2012) in perhaps the only within-individual study linking work engagement to work-family enrichment (or facilitation). ${ }^{2}$ However, the study by Culbertson et al. assessed work-family facilitation with a scale that included both the work causes and their effects (i.e., they asked participants to rate the extent to which skills, behaviors or moods from work had a positive impact on their home life) and did not assess any family outcomes directly. In contrast, we focus on (a) family satisfaction and (b) workfamily balance as end outcomes that indicate work-family enrichment and we propose:

Hypothesis 1: Daily work engagement will be positively associated, within individuals, with daily family satisfaction such that employees will be more satisfied with their family lives on days when they are more, as compared to less, engaged at work.

Hypothesis 2: Daily work engagement will be positively associated, within individuals, with daily work-family balance such that employees will experience better workfamily balance on days when they are more, as compared to less, engaged at work. Having proposed that engagement has positive effects on family life when conceptualized as a daily (time-varying) construct that is associated with contextual work resources (ten Brummelhuis \& Bakker, 2012), we turn our attention to one psychological mechanism that might explain such positive effects. As noted, one process that has been proposed as a linkage in the work-family enrichment process is work-family interpersonal capitalization (Culbertson et al., 2012; Ilies et al., 2011), which is defined as an active behavioral response to positive work events and experiences by which the employee shares positive work experience with his or her spouse at home (Ilies, Keeney, \& Goh, 2015). As we explained earlier, work engagement is associated with positive feelings that can be conceptualized as contextual resources (significance, meaningfulness and pride) as specifically mentioned by Schaufeli, Bakker, and Salanova (2006), in their description of the dedication dimension of work engagement: "Dedication refers to being strongly involved in

\footnotetext{
${ }^{2}$ Also, Rodríguez-Muñoz et al. (2014) found that daily work engagement was related to daily happiness, measured with the Kunin (1955) faces scale at home.
} 
one's work and experiencing a sense of significance, enthusiasm, inspiration, pride, and challenge" (p. 702).

We contend that sharing positive work experiences is more likely on days when one has been highly engaged at work because of the high levels of resources such as the meaningfulness and pride associated with work engagement. Indeed, Gable, Reis, Impett, and Asher (2004, p. 241), in their article including studies of interpersonal capitalization in dating couples and married adults (studies 2 and 3), specifically propose that pride might be the specific positive emotion most closely associated with interpersonal capitalization because "in addition to enhancing one' s own valuing of personal events or achievements through the process of reflected appraisal, pride may also engender engagement and a sense of connection with others." Pride is also closely connected to meaningfulness; with some authors going as far as to suggest that "pride affords an indirect thus potentially less reactive measure of meaning" (Nakamura, 2013, p. 565), and feelings of both pride and meaningfulness are considered part of the work engagement experience (Schaufeli et al., 2002).

Although work engagement may imply debate and arguments and not only positive experiences, if work engagement promotes sharing, it follows that to the extent to which employees have some positive experiences at work (at least on some days, and we believe that this is more likely on days when they experience high work engagement), work engagement would be positively related to work-family interpersonal capitalization.

Hypothesis 3: Daily work engagement will be positively associated, within individuals, with work-family interpersonal capitalization such that employees will be more likely to capitalize on positive work events and experiences on days when they are more, as compared to less, engaged at work.

Furthermore, work-family interpersonal capitalization is specifically considered "a mechanism through which experiences in the work domain enrich the quality of life in the family domain" (Ilies et al., 2011, p. 118) and thus we believe it operates as such to explain the effects of work engagement on family life. As we explained earlier, work engagement 
entails contextual resources (e.g., pride, meaningfulness) and these resources produce a desire to share work events or experiences in the family; then when employees share positive work events or experiences at home (i.e., they engage in work-family interpersonal capitalization), family satisfaction and work-family balance increase (these are personal resources). In sum, work engagement creates contextual resources that lead to the development or gain of personal resources (family satisfaction and work-family balance) through work-family interpersonal capitalization. Thus, we propose that the process of work-family interpersonal capitalization, after an engaging day at work, should enhance the quality of family life. Indeed, previous research has shown that work-family interpersonal capitalization is positively associated with both marital satisfaction (Ilies et al., 2011) and life satisfaction (Ilies, Keeney, \& Goh, 2015).

The sharing act itself, as a social interaction, should make individuals believe that harmony, equilibrium, and integration between work and family roles has been achieved (Voydanoff, 2005), increasing work-family balance. Furthermore, "sharing events with others may build social resources by fostering positive social interactions," (Gable et al., 2004, p. 229) which is consistent with the WH-R model, and such social resources should increase well-being in the family domain. Therefore, work-family interpersonal capitalization should serve as a linking pin between the engaged work experience and family outcomes, such that the effects of daily work engagement on family satisfaction and work-family balance should be mediated by this behavioral mechanism:

Hypothesis 4: Daily work-family interpersonal capitalization will mediate the withinindividual relationship between daily work engagement and daily family satisfaction.

Hypothesis 5: Daily work-family interpersonal capitalization will mediate the withinindividual relationship between daily work engagement and daily work-family balance.

To reiterate, we hypothesized a work-family enrichment process from work engagement to work-family interpersonal capitalization to family life based on the W-HR 
model (ten Brummelhuis \& Bakker, 2012). Yet there is an important assumption regarding a potential boundary condition for the work-family enrichment process in the W-HR model. That is, ten Brummelhuis and Bakker (2012, p. 548) proposed that key resources, which refer to stable personal characteristics, can "facilitate the selection, alternation, and implementation of other resources." They further proposed that work-family enrichment is more likely among persons who possess key resources, as these high-level resources could strengthen the positive relationship between contextual resources (e.g., work resources) and personal resources.

We propose that intrinsic motivation, which refers to a tendency to seek intrinsic interests or enjoyments from various activities (Amabile, Hill, Hennessey, \& Tighe, 1994; Ryan \& Deci, 2000), is one of the key resources that strengthen the work-family enrichment process starting with work engagement. We conceptualize and measure intrinsic motivation as a construct reflecting between-individual differences which assumes that the extent to which individuals are intrinsically motivated is at least somewhat stable (over the duration of our study), and such conceptualization has been supported in several existing studies (Amabile et al., 1994; Gagné \& Deci, 2005; Grant, 2008) and is also consistent with the conceptualization of key resources as relatively stable personal characteristics in the W-HR model of ten Brummelhuis and Bakker (2012).

In short, we would expect that more intrinsically motivated employees would experience higher (average) work engagement (although we do not formally hypothesize this main effect), and we also believe that intrinsic motivation should influence the strength of the positive relationship between work engagement and work-family interpersonal capitalization as suggested by the W-HR model (ten Brummelhuis \& Bakker, 2012). That is, in the W-HR model, key resources (e.g., individual characteristics such as optimism or self-esteem) are thought to make the other resources, such as the volatile emotional resources associated with work engagement, more effective. Furthermore, ten Brummelhuis and Bakker specifically 
propose that employees who "have more resources are more likely to experience work-family enrichment" (p. 553-554) and this is exactly what we predict with respect to intrinsic motivation as a key resource in our model. Of note is that the interactive effect between work engagement and intrinsic motivation suggested by the W-HR model is entirely consistent with person-environment fit models specifying that people derive more emotional benefits from behaviors and situations that are concordant with their own personal characteristics (Côté \& Moskowitz, 1998) because work engagement is concordant with intrinsic motivation (Meyer, 2014; Meyer, Gagné, \& Parfyonova, 2010; Salanova \& Schaufeli, 2008). In sum, we expect that those with higher intrinsic motivation, as a key resource, would benefit more, in terms of emotional resources such as pride and meaningfulness (compared to those lower on intrinsic motivation) from work engagement, and thus would be more likely to engage in work-family interpersonal capitalization at home.

Hypothesis 6: Employees' intrinsic motivation will moderate the within-individual relationship between daily work engagement and daily work-family interpersonal capitalization, such that the relationship will be more positive for employees whose intrinsic motivation is higher, compared to those with lower intrinsic motivation.

In addition to its effect on the work engagement-interpersonal capitalization relationship, we also examine whether intrinsic motivation influences the indirect effects of work engagement on the two family outcomes that reflect work-family enrichment through work-family interpersonal capitalization. That is, we examine whether the moderating (firststage) effect that we hypothesized (Hypothesis 6) translates into moderated mediation effects on the end outcomes to answer the question of whether the strength of work-to-family enrichment, as initiated from an engaged experience at work and mediated through sharing positive work experiences with spouses, depends on employees' intrinsic motivation.

\section{METHOD}

\section{Sample}


Participants in the current study were recruited from a large bank in a city located in northern China. As a key part of the study involved employees' ratings of their interpersonal interactions with spouses, only participants who were married and were living together with their spouses were eligible to participate. Before conducting the survey, our research team and the human resource management (HR) department of the bank screened all 637 full-time employees and identified 449 of them who qualified for the study. Then the HR department sent an invitation letter to these 449 employees, inviting their voluntary participation. One hundred and twenty-nine employees (28.7\% of employees who met our criteria and $20.3 \%$ of all employees) and their spouses signed up to participate in the study. Four participants were eliminated from the analyses due to a substantial amount of missing data, leaving a final sample of 125 employees. The majority of the sample was female (77.6\%) and had a university degree $(88.8 \%)$. The average age of participants was 28.9 years $(S D=2.88)$; average job tenure was 6.2 years $(S D=3.30)$. Participants worked an average of 42.8 hours per week $(S D=5.24)$, and were employed in a variety of positions: $63.2 \%$ were bank tellers, $12 \%$ were customer service managers, $6.4 \%$ were sales managers, and $18.4 \%$ were back office staff.

As mentioned, in addition to sampling employees, we also invited employees' spouses to participate in our study and complete a short daily survey reporting their perceptions or feelings about their family life every evening. One hundred and twenty-four out of 125 employees' spouses provided useful data in the study. The average age was 30.1 years $(S D=$ 3.01), and the majority of them had a full-time job (96.8\%) and held a university degree (71.7\%). Each participating couple received a gift (a household product) valued at about \$200 from the research team as a reward for their participation.

\section{Procedure}


The data were collected using experience sampling methodology (ESM). At the beginning of the study, participants (both employees and spouses) completed a one-time survey that assessed demographics and individual-level variables (e.g., intrinsic motivation). Then, focal participants (i.e., employees) were asked to respond to three daily surveys over two consecutive weeks that included 10 weekdays. Employees' spouses were asked to respond to one daily survey every evening over the 10 weekdays. All surveys involved in the current study were implemented using a web-based survey platform and the links of surveys were sent to participants through a mobile messaging application.

Of the three daily surveys for focal participants, two of them were administered during working time while the other one was administered in the evening when participants were at home. Like other authors (e.g., Culbertson et al., 2012), we chose a fixed-time schedule, mainly for convenience. To enhance the ecological validity of our experience-sampling measurement, we measured constructs where they occur or they are experienced in their natural environment, therefore, as in previous research (e.g., Ilies, Schwind, Wagner, DeRue, \& Ilgen, 2007; Sonnentag \& Bayer, 2005) we measured work variables at work, and family variables at home. Specically, on each morning of the study, participants were sent the link to the first daily survey at 9:00 a.m. They were asked to report their positive affect, negative affect, and state job satisfaction. The link to the second daily survey was sent to participants at 4:30 p.m. This survey asked participants to report their positive affect, negative affect, job satisfaction and daily work engagement. Then, each evening at 8:30 p.m., participants received the link to the last daily survey that assessed participants' positive affect, negative affect, work-family interpersonal capitalization, daily family satisfaction, and daily perceptions of work-family balance. At the same time every evening, employees' spouses would also receive the link to their daily survey assessing their family satisfaction and affective states. 
To increase participation, a reminder signal was sent to participants who did not finish the survey within half an hour. All participants were given a one-hour window to respond to the survey. In total, focal participants completed 3,715 out of total possible 3,750 daily surveys (125 participants $\times 30$ daily surveys). Spouses completed 1,221 out of total possible 1,240 daily surveys (124 spouses $\times 10$ daily surveys).

\section{Measures $^{3}$}

Daily Work Engagement. We used eight items from the short-form Utrecht Work Engagement Scale (UWES) of Schaufeli et al. (2006) to assess participants'state work engagement. ${ }^{4}$ Bakker and Leiter (2010) suggested that the frequency time anchors in the original UWES scale do not fit for measuring state engagement, thus, like other authors (e.g., Culbertson et al., 2012; Sonnentag, 2003; Xanthopoulou et al., 2009a, 2009b), we used agreement anchors in the current study. Participants were asked to indicate the extent to which each of the given statements described their feelings using a 7-point Likert scale ranging from $1=$ strongly disagree to 7 = strongly agree. Sample items include "I feel bursting with energy" and "I am immersed in my job." Coefficient alpha for this scale, averaged over the 10 days of the data collection, was .90 .

Work-Family Interpersonal Capitalization. Participants were asked to indicate the extent to which they agree or disagree with three statements as they apply to their interactions with their spouses on each evening, using a 7-point Likert scale ranging from $1=$ strongly disagree to 7 = strongly agree. The three statements, written specifically for this study, were: "I shared some interesting work events with my spouse," "I told my spouse about some happy events at work," and "I shared my work progress with my spouse." Coefficient alpha for this scale, averaged over the 10 days of the study, was .93 .

\footnotetext{
${ }^{3}$ All measures involved in the current study were in Chinese. We adopted the translation-back translation procedure (Brislin, 1970) to ensure that all English-based measures were accurately translated.

${ }^{4}$ One item ("when I get up in the morning, I feel like going to work") was eliminated from the original 9-item scale because we did not change the wording for this item to match our measuring approach focused on state engagement.
} 
Daily Family Satisfaction. Daily family satisfaction was measured with a modified version of a 3-item scale used originally by Kopelman et al. (1983), to assess daily scores. Participants were asked to indicate their agreement to given statements using a 7-point Likert scale ranging from $1=$ strongly disagree to $7=$ strongly agree. A sample item is "Today, I am satisfied with my family". Coefficient alpha for this scale, averaged over 10 days of the data collection, was .74.

Daily Work-Family Balance. We adapted a 6-item scale developed by Carlson et al. (2009) to measure participants' daily perceptions of work-family balance. Instead of asking participants to indicate their perceptions of work-family balance in a general sense, we asked them to indicate their agreement to several statements on a daily basis, using a 7-point Likert scale ranging from $1=$ strongly disagree to $7=$ strongly agree. Sample items of the scale include "I have done a good job of meeting the role expectations of critical people in my work and family life today" and "I have been accomplishing both my work and family responsibilities today." Coefficient alpha for this scale, averaged over 10 days of the data collection, was .94.

Affect. We used the Positive and Negative Affect Schedule (PANAS; Watson \& Clark, 1994) to measure participants' state affect. The PANAS scale consists of 20 adjective descriptors of affect. Sample adjective descriptors for positive affect are "interested," "enthusiastic," and "determined." Sample adjective descriptors for negative affect are "upset," “irritable," and "hostile." Participants were asked to indicate the extent to which each adjective described their momentary affective state using a 7-point Likert scale ranging from $1=$ not at all to $7=$ extremely much. Coefficient alphas for the positive affect scale and the negative affect scale were .80 and .83 , respectively.

Intrinsic Motivation. We measured intrinsic motivation in the initial one-time survey at the beginning of the study. A 4-item scale adapted by Grant (2008) based on Ryan and 
Connell's (1989) original scale was used. We asked participants a question "why are you motivated to do your work" followed by four items as possible answers. Participants were asked to indicate their agreement to the four items using a 7-point Likert scale ranging from 1 $=$ strongly disagree to 7 = strongly agree. The four items were "Because I enjoy the work itself," "Because it's fun," "Because I find the work engaging," and "Because I enjoy it." As the item "Because I find the work engaging" has clear content overlap with the work engagement measure, in testing the hypothesized relationships involving intrinsic motivation (i.e., H6 and the moderated mediation effects), we excluded this item and used the 3-item measure instead. Coefficient alphas for the four-item scale and the three-item scale were .93 and .89 , respectively. The correlation between the two scales was .99 $(p<.001)$. The moderation effect and moderated mediation effects, however, did not differ much from the results from the analyses using the original 4-item scale.

\section{Analytic Strategy}

Given the nested nature of our data (i.e., daily observations nested within individuals), we used multilevel path-analytical modeling in Mplus 6.0 (Muthén \& Muthén, 1998-2010) to test all our hypotheses. Specifically, the direct effects of daily work engagement on the two family outcomes and the mediator (i.e., Hypotheses 1 to 3) were tested by using random coefficient models (RCMs; Raudenbush \& Bryk, 2002), the indirect effects of daily work engagement on the two family outcomes (i.e., Hypotheses 4 and 5) were tested by using multilevel mediation models (i.e., lower level mediation or 1-1-1 mediation model; Bauer, Preacher, \& Gil, 2006, p. 143), and finally, the cross-level moderating effect of intrinsic motivation (i.e., Hypothesis 6) and the moderated mediation effects were tested in pathanalytical models involving a level-2 moderator. Before conducting these analyses, all predictors at level 1 were centered relative to each individual's mean (i.e., group-mean centering; Enders \& Tofighi, 2007; Hofmann \& Gavin, 1998) to remove the between- 
individual variance, so that the estimates for level-1 effects represented pure within-individual relations. In testing the cross-level moderation and the moderated mediation, the moderator at level 2 (i.e., intrinsic motivation) was centered using grand mean centering to alleviate potential problems relating to multicollinearity (Hofmann \& Gavin, 1998).

In testing the significance of the indirect effects of daily work engagement on the family outcomes (i.e., Hypotheses 4 and 5), we conducted Monte Carlo simulations with 20,000 replications and computed $95 \%$ confidence intervals. This procedure accurately reflects the asymmetric nature of the sampling distribution of an indirect effect in multilevel models (Bauer et al., 2006; Preacher \& Selig, 2010, 2012) and has been used in several recent studies (e.g., Lanaj, Johnson, \& Barnes, 2014; Wang, Liu, Liao, Gong, Kammeyer-Muller, \& Shi, 2013). To examine the two moderated mediation effects, we tested the indirect effects of daily work engagement on daily family satisfaction/daily work-family balance via daily workfamily interpersonal capitalization at higher $(+1 S D)$ and lower levels $(-1 S D)$ of intrinsic motivation using the method introduced by Bauer and coauthors (2006).

\section{Model Controls}

To rule out employees' affective states as potential confounds for the estimated mediation effects in the model, we controlled for employees' state affect reported at home when predicting the endogenous variables in all models we estimated. Specifically, we specified the effects of employees' state affect at home on endogenous variables as level-1 fixed slopes. Like other authors (e.g., Wang et al., 2013; Luksyte, Avery, \& Yeo, 2015) we specified the influences of control variables as fixed effects because we were not interested in between-individual variation in these effects. We also investigated whether controlling for the effects of employees' state positive/negative affect reported in the afternoon on the mediator (i.e., daily work-family interpersonal capitalization) would alter our results in any way. However, we found that the effects of both variables on work-family interpersonal 
capitalization were not significant, and the inclusion of these two variables did not alter the results of our model in any substantial way. Thus, we only control for positive and negative affect at home in the final analyses.

\section{RESULTS}

Before testing the within-individual hypotheses, it was necessary to examine whether there was sufficient within-individual variance for the level-1 variables in the current study. To do so, we tested a number of null models using Mplus. Table 1 presents the proportion of variance for all level-1 variables in the current study. As can be seen from the table, the percentage of within-individual variance of level-1 variables ranged from $29 \%$ to $49 \%$, indicating there was substantial within-individual variance in all level-1 variable scores.

Insert Table 1 about here

Table 2 presents the descriptive statistics and correlations between the focal variables in the current study. As can be seen from the table, daily work engagement was significantly correlated with daily work-family balance $\left(r_{\text {within }}=.11, p<.01\right)$ and with daily work-family interpersonal capitalization $\left(r_{\text {within }}=.09, p<.01\right)$, which provided preliminary support for Hypotheses 2 and 3. However, daily work engagement was not significantly correlated with daily family satisfaction $\left(r_{\text {within }}=.05, p>.05\right)$.

Insert Table 2 about here

\section{Tests of Hypotheses}

Hypotheses 1 to 3 posited the direct effects of daily work engagement on family satisfaction, work-family balance, and work-family interpersonal capitalization, respectively. First, we tested Hypotheses 1 and 2 simultaneously in the same path-analytical model, in which both family satisfaction and work-family balance were included as dependent variables. 
Results showed that the direct effect of daily work engagement on daily family satisfaction was not significant $(B=.03, S E=.04, p>.05)$, failing to support H1; while the direct effect of daily work engagement on daily work-family balance was significant $(B=.10, S E=.04, p$ $<.05$ ), thus supporting H2. For Hypothesis 3, we tested it in a separate path-analytical model with work-family interpersonal capitalization as the only outcome because unlike the other two family constructs, work-family interpersonal capitalization is a mediator, and not an end outcome, in the final model (described below). ${ }^{5}$ Results showed that the direct effect of daily work engagement on daily work-family interpersonal capitalization was significant $(B=.15$, $S E=.07, p<.05)$, providing support for H3. These results are presented in Table 3.

Insert Table 3 about here

Hypothesis 4 stated that daily work-family interpersonal capitalization would mediate the relationship between daily work engagement and daily family satisfaction. Similarly, Hypothesis 5 predicted that daily work-family interpersonal capitalization would mediate the effect of daily work engagement on daily work-family balance. To test whether these two mediation effects are statistically significant, we estimated the two 1-1-1 indirect effects simultaneously in a path-analytical model. The unstandardized path coefficients of this model are presented in Table 4. Following Bauer and coauthors' (2006) recommendation of estimating indirect effects in random-effect models, the indirect effects were computed as the product of the $a$ path (daily work engagement to work-family interpersonal capitalization) and the $b$ path (work-family interpersonal capitalization to family satisfaction or work-family balance), plus the covariance between them (i.e., indirect effect $=a \times b+\operatorname{cov}(a, b))$. In support of Hypothesis 4, the estimate for the indirect effect of work engagement on family satisfaction through work-family interpersonal capitalization was .064, with a $95 \%$ confidence

\footnotetext{
${ }^{5}$ The results were essentially the same when we included work-family interpersonal capitalization in the same model with family satisfaction and work-family balance.
} 
interval (CI) of [.037, .097]. Similarly, the estimate for the indirect effect of daily work engagement on daily work-family balance via daily work-family interpersonal capitalization was .035 , with a $95 \%$ CI of $[.016, .058]$. Thus Hypothesis 5 was also supported. The final model explained $24 \%$ of the within-individual variance in family satisfaction and $14 \%$ of the within-individual variance in work-family balance.

Insert Table 4 about here

Hypothesis 6 posited that employees' intrinsic motivation would interact with their daily work engagement such that the positive relationship between daily work engagement and daily work-family interpersonal capitalization would be stronger for employees whose intrinsic motivation is higher (vs. lower). This cross-level moderation effect was tested in a model that included the level-2 moderator (i.e., intrinsic motivation) as a predictor of the random slope of the effect of daily work engagement on daily work-family interpersonal capitalization. As shown in Table 5, intrinsic motivation was positively related to the random slope between daily work engagement and daily work-family interpersonal capitalization ( $B$ $=.11, S E=.05, p<.05)$.

Insert Table 5 about here

Following the recommendations of Cohen, Cohen, West, and Aiken (2003), we plotted this interaction effect at conditional values of intrinsic motivation (1 standard deviation $[S D]$ above and below the mean) in Figure 2. We also conducted a simple slope analysis as recommended by Preacher, Curran, and Bauer (2006). The results showed that the positive relationship between daily work engagement and daily work-family interpersonal capitalization was significant at higher levels (i.e., $+1 S D$ ) of intrinsic motivation (simple slope $=0.28, t=2.89, p<.01)$, but not at lower levels (i.e., $-1 S D)$ of intrinsic motivation 
( simple slope $=0.02, t=0.28, p>.05)$, which means that daily work engagement positively related to daily work-family interpersonal capitalization only for employees with relatively high intrinsic motivation. Thus Hypothesis 6 was supported.

Insert Figure 2 about here

Extending Hypothesis 6, we suggested that the indirect relationship between daily work engagement and daily family satisfaction/daily work-family balance would be stronger for employees whose intrinsic motivation is higher (vs. lower). To test these two moderated mediation effects, we estimated the indirect effects of daily work engagement on the two outcomes via daily work-family interpersonal capitalization at higher $(+1 S D)$ and lower levels (-1 SD) of employees' intrinsic motivation following the method of Bauer et al. (2006). For daily family satisfaction, the indirect effect was .077 with a $95 \%$ CI of $[.033, .120]$ when intrinsic motivation was higher, whereas the indirect effect was .026 with a $95 \%$ CI of [$.011, .064]$ when intrinsic motivation was low. The estimate of the difference between the two indirect effects was .050 with a $95 \%$ CI of $[.009, .091]$. Thus, the first proposed moderated mediation was supported, with the results revealing an indirect effect of daily work engagement on daily family satisfaction via daily work-family interpersonal capitalization only for employees whose intrinsic motivation is relatively high. Similarly, for daily workfamily balance, the indirect effect was .034 with a 95\% CI of $[.011, .058]$ when intrinsic motivation was higher, whereas the indirect effect was -.001 with a 95\% CI of [-.031, .029] when intrinsic motivation was lower, and the estimate of the difference between the two indirect effects was .035 with a $95 \%$ CI of $[.009, .062]$. Thus, the second proposed moderated mediation was also supported.

\section{Supplementary Analyses}


Although our analyses showed that work-family interpersonal capitalization mediated the effects of daily work engagement on daily family outcomes, it is possible that some other constructs may explain these effects. Besides work engagement, we also measured employees' job satisfaction and positive affect in the afternoon. To examine whether these two variables mediate the effects of work engagement on family outcomes, we tested six indirect effects with either job satisfaction or positive affect as a mediator and with one of the three family variables (i.e., work-family interpersonal capitalization, family satisfaction, and work-family balance) as the outcome. Results showed, however, that only one of the six indirect effects was supported, which was the indirect effect of work engagement on workfamily balance via job satisfaction (estimate $=.09,95 \% \mathrm{CI}=[.01, .12])$. The causal explanation that reflects this effect, that work engagement produces job satisfaction which, in turn, spills over to the family domain and increases work-family balance is definitely plausible, although it is perhaps not very surprising. Also, given that the other two indirect effects of work engagement through job satisfaction were not supported (work engagement to job satisfaction to work-family interpersonal capitalization, estimate $=-.03,95 \% \mathrm{CI}=[-$ $.10, .05]$; work engagement to job satisfaction to family satisfaction, estimate $=-.02,95 \% \mathrm{CI}$ $=[-.08, .04])$, the overall hypothesis that job satisfaction mediates the effects of work engagement on the three outcomes has weak support. Furthermore, we tested whether a causal ordering whereby work engagement influences work-family balance which, in turn, influences both work-family interpersonal capitalization and family satisfaction. Analyses showed support for the indirect effect of work engagement on work-family interpersonal capitalization (estimate $=.07,95 \% \mathrm{CI}=[.02, .11])$ but not on family satisfaction (estimate $=.001,95 \% \mathrm{CI}=[-.04, .04])$, giving only partial support for work-family balance as a mediator. 
Although we did not hypothesize any relationships involving spouse-rated variables in our conceptual model, following Rodríguez-Muñoz, et al. (2014) we conducted a supplementary analysis to investigate if there were any crossover effects that could provide further evidence for the validity of our findings. As can be seen from Table 2, among all the focal variables at the within-individual level, only employee's daily family satisfaction was significantly correlated with spouses' daily family satisfaction $\left(r_{\text {within }}=.11, p<.001\right) .{ }^{6} \mathrm{We}$ further tested the indirect effect of employees' daily work-family interpersonal capitalization on spouses' daily family satisfaction via employees' daily family satisfaction in a separate 11-1 mediation model, in which we controlled for the effects of spouses' affect in the evening on family satisfaction. The estimate of the indirect effect using the Monte Carlo simulation was .033, with a 95\% CI of [.011, .058], indicating that employees' daily family satisfaction mediated the relationship between their daily work-family interpersonal capitalization and their spouses' family satisfaction. ${ }^{7}$

\section{DISCUSSION}

The present study adds to the literature linking work and family by testing the hypothesis that employees' daily work engagement can exert a positive influence on their family lives through a behavioral mechanism of sharing positive work experiences with their spouses. The data collected for the study offered support for this general hypothesis, as we found evidence for two day-to-day (within-individual) indirect effects from work engagement to family satisfaction and to work-family balance through work-family interpersonal capitalization. Moreover, the results of the present study also indicated that the proposed work-family enrichment process is contingent on individuals' intrinsic motivation.

Specifically, our findings showed that daily work engagement relates positively to work-

\footnotetext{
${ }^{6}$ In measuring spouses' daily family satisfaction, we used the same scale (Kopelman et al., 1983) as that administered to employees.

${ }^{7}$ We further tested a serial mediation model in which employee's daily work engagement exerted its influence on spouses' family satisfaction through employees' work-family interpersonal capitalization and family satisfaction sequentially. However, this mediation effect was not supported (estimate $=.01,95 \% \mathrm{CI}=[-.01, .02]$ ).
} 
family interpersonal capitalization only for employees with relatively high intrinsic motivation. Finally, the results also showed that the indirect relationships between employees' daily work engagement and the daily family outcomes (i.e., family satisfaction and workfamily balance) through work-family interpersonal capitalization are only realized for those with relatively high intrinsic motivation, which might explain previous null or opposite results (e.g., Halbesleben et al., 2009). These were our main findings.

There were also relationships that we proposed but we did not find. In Hypothesis 1 we proposed that daily work engagement has a direct (main) effect on family satisfaction, and this hypothesis was not supported by the data. There are several possible explanations for this lack of empirical support. First, even though the linear effect of daily work engagement on daily family satisfaction was not supported, we found a significant curvilinear withinindividual effect of daily work engagement on daily family satisfaction showing an increasingly positive direct effect of work engagement on family satisfaction, which could explain why the linear effect was not significant. Second, as we explain in more detail later, we found evidence suggesting that the extent to which work engagement fluctuates from day to day qualifies (in between-individual analyses), or changes the direction of (in cross-level analyses), the effect of work engagement on family satisfaction, which may explain why a main effect was not supported.

\section{Contributions}

We believe that the current research contributes to the applied psychology and organizational behavior literatures in several aspects. First, at a general level, our findings show that experiencing daily work engagement can be beneficial for employees' family lives, yet these benefits were contingent on the intrinsic motivation of the employees in our study. Given the contrasting views in the literature with some suggesting that work engagement depletes resources and brings about negative family outcomes (e.g., George, 2011; 
Halbesleben et al., 2009) while others suggesting that work engagement is beneficial for family life (e.g., Culbertson et al., 2012; Rodríguez-Muñoz et al., 2014), we believe this is an important contribution in enriching our understanding of the consequences of work engagement. Also, our theorizing leading to the within-individual model linking work engagement to family life through work-family interpersonal capitalization that we tested contributes to the literature by integrating processes that were only studied separately before (Culbertson et al., 2012; Ilies et al., 2011; Rodríguez-Muñoz et al., 2014).

Second, the boundary conditions for the effects of work engagement on family life that we identified may explain previous inconsistent findings, and can also lead to interesting future research. In a way, our examination of the interactive effects of work engagement and intrinsic motivation is akin to examining the role of employees' motives for being engaged in the process linking work engagement to family outcomes. Drawing a parallel to the literature on motives for organizational citizenship behavior (e.g., Rioux \& Penner, 2001), we suggest that future research should examine the role of intrinsic motivation in perhaps qualifying the effects of work engagement on other outcomes as well. Although this was not formally hypothesized, we also found in additional analyses that individuals' characteristic variability in the daily work engagement scores (i.e., the extent to which their work engagement fluctuates from day to day) moderated the beneficial effect of work engagement on the family, in both between-individual and cross-level analyses, and also had a positive main effect on family satisfaction. This finding concerning the variability in day-to-day work engagement suggests support for the argument that chronic (high level and low variability) work engagement can be detrimental to employees (e.g., George, 2010; Halbesleben et al., 2009) and is consistent with George's (2010) suggested beneficial effects of fluctuating levels of work engagement for various indicators of employee performance. We suggest that future research should employ research designs similar to ours, yet perhaps over longer time periods, 
to examine the effects of day-to-day variability in work engagement on other outcomes, such as the performance indicators suggested by George.

We also examined a unique behavioral mechanism linking the experience of work to family well-being, which complements existing research on this topic. In their seminal work on work-family enrichment, Greenhaus and Powell (2006) suggested two paths linking work and family roles: an instrumental path, which depicts the direct translation of resources in one role into another role; and an affective path, which depicts the work-family enrichment from an affective perspective. We extend this two-path model by proposing and testing a behavioral linkage between the work and family roles. Our findings suggest that sharing positive work experiences with spouses, as a behavioral action spurred by being engaged at work, may help translate the contextual resources gained from work experiences to the development of personal resources (satisfaction and work-family balance) in the family domain. Yet we have not measured actual resources, and thus we suggest that future research should measure contextual resources such as those that we described in the introduction (e.g., meaningfulness, pride) to test whether our reasoning that work engagement elicits sharing because of the feelings of pride and meaningfulness associated with it is correct.

Finally, the methodology that we used in this study makes a contribution to research on the outcomes of work engagement. That is, to test our hypotheses we adopted a dynamic conceptualization of work engagement by investigating it as a state at the within-individual level through a daily study, which follows the suggestions of several authors (Bakker et al., 2011; Sonnentag, 2011; Xanthopoulou et al., 2009a). ${ }^{8}$ As noted in the introduction, we believe that this methodology is best suited for examining the effects of work engagement on the family domain, and it allowed us to examine the influence of the day-to-day variability in work engagement scores on the family outcomes, as we explained above. We also found an

\footnotetext{
${ }^{8}$ We also measured engagement at work while the family outcomes were measured at home, thus our findings have enhanced ecological validity.
} 
indirect effect of work-family interpersonal capitalization on spouses' satisfaction, through focal individuals' (employees') family satisfaction, but not a direct effect of interpersonal capitalization (or of work engagement) on spouses' family satisfaction. This is consistent with theory on interpersonal capitalization as this behavior is thought to primarily affect one's own well-being through processes such as the re-experience of the events which increases their salience and accessibility in memory, or social verification by sharing the events with the spouse (Gable et al., 2004; Ilies et al., 2011).

\section{Limitations and Directions for Future Research}

As with any research, our study has certain limitations that need to be discussed. The first limitation relates to our use of self-reports to assess the constructs in the proposed model. However, we believe that the use of self-reports in our study is adequate for several reasons. First, variables such as work engagement, family satisfaction, and work-family balance capture employees' psychological experience or attitudinal evaluations, and thus are best reported by the employees themselves. Second, there is evidence showing that individuals might be the best informed source of behavioral ratings (Berry, Carpenter, \& Barratt, 2012), thus it should also be appropriate to assess work-family interpersonal capitalization based on self-reports. Third, our research design by which variables in the model were assessed at separate points in time (i.e., afternoon and evening) should alleviate the common method bias concern (Podsakoff, MacKenzie, Lee, \& Podsakoff, 2003). Finally, and importantly, common method bias is not of concern when testing cross-level interactions (Lai, Li, \& Leung, 2013). Nevertheless, future research can involve assessments for some variables (e.g., work-family interpersonal capitalization) from other sources (e.g., spouses or partners) to test the relationships documented here.

Second, we have made a case that work engagement enhances family life and workfamily balance through work-family interpersonal capitalization, thus we treated interpersonal 
capitalization as a mediator, and we found support for this mediated effect. However, conceptually, work-family interpersonal capitalization enhances the effects of positive work events and experiences (Ilies et al., 2011), thus it may operate as a moderator (yet concerning the effects of positive work events and not of work engagement), and indeed has been studied as such by Culbertson et al. (2012) who found that work-family interpersonal capitalization interacted with daily work engagement to predict work-family facilitation. It is possible that interpersonal capitalization, as a behavioral reaction to work events, acts similarly (for positive experiences though, not for stressors) to psychological detachment which is a construct that "seems to be both a mediator and a moderator in the relationship between job stressors on the one hand and strain and poor well-being on the other hand" (Sonnentag \& Fritz, 2015, p. 72). Not only do we believe that our treatment of work-family interpersonal capitalization as a mediator is appropriate for our study design, but also we believe examining the indirect effects from work engagement to family life represents a unique contribution of our study because we identify and test a behavioral work-family enrichment mechanism linking daily work engagement to family life.

Third, although the results in our study supported the indirect effects of daily work engagement on family satisfaction/work-family balance through work-family interpersonal capitalization, due to the fact that both work-family interpersonal capitalization and family outcomes were reported by employees themselves in the evening, it is entirely possible that family satisfaction and work-family balance promoted sharing positive work events with spouses, rather than vice versa. In this sense, our data do not speak to the issue of causality. To address this issue methodologically, we tested two separate 1-1-1 indirect effect models with either family satisfaction or work-family balance mediating the effect of work engagement on work-family interpersonal capitalization. Results supported the mediating effect of work-family balance, which is indeed plausible yet outside the scope of the current 
study. The mediating effect of family satisfaction, however, was not supported. It is also possible that the occurrence of positive events at work makes people more engaged, which in turn affects sharing at home, yet we cannot test this possibility because we did not measure the occurrence of positive events at work. Nevertheless, as we describe in the section on supplementary analyses, we did test eight alternative causal orderings among the constructs that we measured, and found that two of those alternative indirect effects are indeed plausible (the effect of work engagement on work-family balance through job satisfaction and the effect from work engagement to interpersonal capitalization through work-family balance). Therefore, as with all correlational studies, the issue of causality remains a concern, and future research should attempt to overcome this limitation either by separating the assessments of work-family interpersonal capitalization and family outcomes temporally or by using different sources to assess these constructs.

Fourth, in building support for our hypotheses, we drew on the W-HR model (ten Brummelhuis \& Bakker, 2012) and adopted the resource-accumulation process as the underlying mechanism for work-family enrichment. Yet it is possible that the enriching effects of work engagement on family life are realized through different mechanisms, such as affective spillover (e.g., Greenhaus \& Powell, 2006). To address this potential confounding effect, we added employees' affective states (both at work and at home) as control variables in our models. The results showed that adding these controls did not change the hypothesized relations in any substantial way, which to some extent alleviated the concern of alternative explanations. In addition, our approach assumes that employees (or at least some of them) have some level of work-family integration that connects their work activities and feelings to the family domain. Yet it is possible that some employees segment their work and family roles; and for those people work engagement would not affect family life. It follows that the extent to which some of the employees in our sample were fully segmenting the work and 
family roles actually makes our results conservative. Future research may try to address these limitations by explicitly asking employees to report their perceived levels of psychological resources at specific times during the day (e.g., after work or after sharing positive work events with spouses or partners) and by measuring work-family role integration.

Finally, to the extent to which high daily work engagement reflects good job performance on that day (Rich, LePine, \& Crawford, 2010), it would influence employees' perceptions that they adequately fulfilled their work responsibilities, which may explain the link between daily work engagement and work-family balance, as work-family balance reflects, in part, adequately fulfilling work responsibilities (but also fulfilling home responsibilities). However, such effect is not likely to be strong, given the low correlation between work engagement and work-family balance. Furthermore, this link can also reflect a causal mechanism by which engagement at work (and fulfillment of work responsibilities) spills over to engagement at home (and fulfillment of family responsibilities) thus explaining why work engagement is related to work-family balance, as we suggested in the introduction. It is also possible that work engagement affects the family, in part, due to the overlap between the measure of engagement that we used and work attitudes (Byrne, Peters, \& Weston, 2016) and the spillover of work attitudes to the family domain (e.g., Ilies, Wilson, \& Wagner, 2009). Yet the fact that work engagement had a main effect only on work-family balance (and not on family satisfaction), suggests that such an effect is not the primary explanation for our findings. Nevertheless, to examine the possibilities mentioned above, future research should measure work engagement with alternative measures (e.g., Rich et al., 2010), and also examine engagement at home and also family role performance as outcomes of work engagement.

\section{Conclusion}


We have developed and tested a multilevel model linking work engagement to family life through work-family interpersonal capitalization, at the within-individual level, and examining the role of intrinsic motivation in influencing the strength of the within-individual relationships. Our findings show that on days when employees are more engaged at work they are also more likely to engage in work-family interpersonal capitalization at home, by discussing positive work events and experiences, and this behavior, in turn, influences family satisfaction and work-family balance. The results also showed that those who are more intrinsically motivated benefit more from work engagement in that they exhibit stronger relationships among work engagement and the family variables. We believe our theorizing and findings advance theory and research on the consequences of work engagement for family life, and we hope that this study will also stimulate interesting future research. 


\section{REFERENCES}

Amabile, T. M., Hill, K. G., Hennessey, B. A., \& Tighe, E. M. (1994). The Work Preference Inventory: assessing intrinsic and extrinsic motivational orientations. Journal of Personality and Social Psychology, 66, 950-967. http://dx.doi.org/10.1037/00223514.68 .4 .580

Bakker, A. B. (2014). Daily fluctuations in work engagement: An overview and current directions. European Psychologist, 19, 227-236. http://dx.doi.org/10.1027/1016$9040 / \mathrm{a} 000160$

Bakker, A. B., Albrecht, S. L., \& Leiter, M. P. (2011). Key questions regarding work engagement. European Journal of Work and Organizational Psychology, 20, 4-28. http://dx.doi.org/10.1080/1359432x.2010.485352

Bakker, A. B., \& Bal, M. P. (2010). Weekly work engagement and performance: A study among starting teachers. Journal of Occupational and Organizational Psychology, 83(1), 189-206. http://dx.doi.org/10.1348/096317909X402596

Bakker, A. B., \& Leiter, M. P. (2010). Where to go from here: Integration and future research on work engagement. In A. B. Bakker \& M. P. Leiter (Eds.), Work engagement: A handbook of essential theory and research (pp. 181-196). New York: Psychology Press.

Bakker, A. B., Petrou, P., \& Tsaousis, I. (2012). Inequity in work and intimate relationships: A Spillover-Crossover model. Anxiety, Stress \& Coping, 25(5), 491-506. http://dx.doi.org/ 10.1080/10615806.2011.619259

Bauer, D. J., Preacher, K. J., \& Gil, K. M. (2006). Conceptualizing and testing random indirect effects and moderated mediation in multilevel models: new procedures and recommendations. Psychological Methods, 11, 142-163.

http://dx.doi.org/10.1037/1082-989x.11.2.142 
Berry, C. M., Carpenter, N. C., \& Barratt, C. L. (2012). Do other-reports of counterproductive work behavior provide an incremental contribution over self-reports? A meta-analytic comparison. Journal of Applied Psychology, 97, 613-636.

http://dx.doi.org/10.1037/a0026739

Brislin, R. W. (1970). Back-translation for cross-cultural research. Journal of Cross-Cultural Psychology, 1, 185-216. http://dx.doi.org/10.1177/135910457000100301

Butler, A. B, Song, Z, \& Ilies, R. (2013). Experience sampling methods for work-family research: A review and research agenda. In J. G. Grzywacz, \& E. Demerouti (Eds.), New frontiers in work and family research (pp. 133-149). East Sussex, UK: Psychology Press.

Byrne, Z. S., Peters, J. M., \& Weston, J. W. (2016). The struggle with employee engagement: Measures and construct clarification using five samples. Journal of Applied Psychology, 101, 1201-1227. http://dx.doi.org/10.1037/ap10000124

Carlson, D. S., Grzywacz, J. G., \& Zivnuska, S. (2009). Is work-family balance more than conflict and enrichment? Human Relations, 62, 1459-1486. http://dx.doi.org/10.1177/0018726709336500

Cohen, J., Cohen, P., West, S. G., \& Aiken, L. S. (2003). Applied multiple regression/correlation analysis for the behavioral sciences. Mahwah, NJ: Erlbaum.

Côté, S., \& Moskowitz, D. S. (1998). On the dynamic covariation between interpersonal behavior and affect: prediction from neuroticism, extraversion, and agreeableness. Journal of Personality and Social Psychology, 75(4), 10321046. http://dx.doi.org/10.1037/0022-3514.75.4.1032

Culbertson, S. S., Mills, M. J., \& Fullagar, C. J. (2012). Work engagement and work-family facilitation: Making homes happier through positive affective spillover. Human Relations, 65, 1155-1177. http://dx.doi.org/10.1177/0018726712440295 
Enders, C. K., \& Tofighi, D. (2007). Centering predictor variables in cross-sectional multilevel models: A new look at an old issue. Psychological Methods, 12, 121-138. http://dx.doi.org/10.1037/1082-989x.12.2.121

Gable, S. L., Reis, H. T., Impett, E. A., \& Asher, E. R. (2004). What do you do when things go right? The intrapersonal and interpersonal benefits of sharing positive events. Journal of Personality and Social Psychology, 87(2), 228-245. http://dx.doi.org/ 10.1037/0022-3514.87.2.228

Gagné, M., \& Deci, E. L. (2005). Self-determination theory and work motivation. Journal of Organizational Behavior, 26, 331-362. http://dx.doi.org/10.1002/job.322

George, J. M. (2010). More engagement is not necessarily better: The benefits of fluctuating levels of engagement. In S. L. Albrecht (Ed.), Handbook of employee engagement: Perspectives, issues, research and practice (pp. 253-263). Cheltenham, UK: Edward Elgar.

George, J. M. (2011). The wider context, costs, and benefits of work engagement. European Journal of Work and Organizational Psychology, 20, 53-59. http://dx.doi.org/10.1080/1359432x.2010.509924

Grant, A. M. (2008). Does intrinsic motivation fuel the prosocial fire? Motivational synergy in predicting persistence, performance, and productivity. Journal of Applied Psychology, 93, 48-58. http://dx.doi.org/10.1037/0021-9010.93.1.48

Greenhaus, J. H., \& Powell, G. N. (2006). When work and family are allies: A theory of work-family enrichment. Academy of Management Review, 31, 72-92. http://dx.doi.org/10.5465/amr.2006.19379625

Grzywacz, J. G., Carlson, D. S., Kacmar, K. M., \& Wayne, J. H. (2007). A multi-level perspective on the synergies between work and family. Journal of Occupational and 
Organizational Psychology, 80, 559-574.

http://dx.doi.org/10.1348/096317906x163081

Halbesleben, J. R., Harvey, J., \& Bolino, M. C. (2009). Too engaged? A conservation of resources view of the relationship between work engagement and work interference with family. Journal of Applied Psychology, 94, 1452-1465. http://dx.doi.org/10.1037/a0017595

Hobfoll, S. E. (2002). Social and psychological resources and adaptation. Review of General Psychology, 6, 307-324. http://dx.doi.org/10.1037/1089-2680.6.4.307

Hofmann, D. A., \& Gavin, M. B. (1998). Centering decisions in hierarchical linear models: Implications for research in organizations. Journal of Management, 24, 623-641. http://dx.doi.org/10.1177/014920639802400504

Ilies, R., Aw, S. S. Y., \& Pluut, H. (2015). Intraindividual models of employee well-being: What have we learned and where do we go from here. European Journal of Work and Organizational Psychology, 24, 827-838. http://dx.doi.org/10.1080/1359432X.2015.1071422

Ilies, R., Keeney, J., \& Scott, B. A. (2011). Work-family interpersonal capitalization: Sharing positive work events at home. Organizational Behavior and Human Decision Processes, 114, 115-126. http://dx.doi.org/10.1016/j.obhdp.2010.10.008

Ilies, R., Keeney, J., \& Goh, Z. W. (2015). Capitalizing on positive work events by sharing them at home. Applied Psychology: An International Review, 64, 578-598. http://dx.doi.org/10.1111/apps.12022

Ilies, R., Schwind, K. M., Wagner, D. T., Johnson, M. D., DeRue, D. S., \& Ilgen, D. R. (2007). When can employees have a family life? The effects of daily workload and affect on work-family conflict and social behaviors at home. Journal of Applied Psychology, 92(5), 1368-1379. http://dx.doi.org/10.1037/0021-9010.92.5.1368 
Ilies, R., Wilson, K. S., \& Wagner, D. T. (2009). The spillover of job satisfaction onto employees' family lives: The facilitating role of work-family integration. Academy of Management Journal, 52, 87-102. http://dx.doi.org/10.5465/AMJ.2009.36461938

Kahn, W. A. (1990). Psychological conditions of personal engagement and disengagement at work. Academy of Management Journal, 33(4), 692-724. http://dx.doi.org/10.2307/256287

Kopelman, R. E., Greenhaus, J. H., \& Connolly, T. F. (1983). A model of work, family, and interrole conflict: A construct validation study. Organizational Behavior and Human Performance, 32, 198-215. http://dx.doi.org/10.1016/0030-5073(83)90147-2

Kunin, T. (1955). The construction of a new type of attitude measure. Personnel Psychology, 9, 65-78. http://dx.doi.org/10.1111/j.1744-6570.1955.tb01189.x

Lai, X., Li, F., \& Leung, K. (2013). A Monte Carlo study of the effects of common method variance on significance testing and parameter bias in hierarchical linear modeling. Organizational Research Methods, 16, 243-269. http://dx.doi.org/10.1177/1094428112469667

Lanaj, K., Johnson, R. E., \& Barnes, C. M. (2014). Beginning the workday yet already depleted? Consequences of late-night smartphone use and sleep. Organizational Behavior and Human Decision Processes, 124, 11-23. http://dx.doi.org/10.1016/j.obhdp.2014.01.001

Luksyte, A., Avery, D. R., \& Yeo, G. (2015). It is worse when you do it: Examining the interactive effects of coworker presenteeism and demographic similarity. Journal of Applied Psychology, 100(4), 1107-1123. http://dx.doi.org/10.1037/a0038755

Meyer, J. P., (2014) Employee commitment, motivation, and engagement: Exploring the links. In Gagné M. (Ed.) Oxford handbook of work engagement, motivation, and selfdetermination theory (pp. 33-49). New York: Oxford University Press. 
Meyer, J. P., Gagné, M., \& Parfyonova, N. M. (2010). Toward an evidence-based model of engagement: What we can learn from motivation and commitment research. In S. Albrecht (Ed.), The handbook of employee engagement: Perspectives, issues, research and practice (pp. 62-73). Cheltenham, UK: Edwin Elgar Publishing.

Muthén, L.K., \& Muthén, B.O. (1998-2010). Mplus User's Guide. Sixth Edition. Los Angeles, CA: Muthén \& Muthén.

Nakamura, J. (2013). Pride and the experience of meaning in daily life. The Journal of Positive Psychology, 8(6), 555-567. http://dx.doi.org/ $10.1080 / 17439760.2013 .830765$

Podsakoff, P. M., MacKenzie, S. B., Lee, J. Y., \& Podsakoff, N. P. (2003). Common method biases in behavioral research: a critical review of the literature and recommended remedies. Journal of Applied Psychology, 88, 879-903. http://dx.doi.org/10.1037/0021-9010.88.5.879

Preacher, K. J., Curran, P. J., \& Bauer, D. J. (2006). Computational tools for probing interactions in multiple linear regression, multilevel modeling, and latent curve analysis. Journal of Educational and Behavioral Statistics, 31, 437-448. http://dx.doi.org/10.3102/10769986031004437

Preacher, K. J., \& Selig, J. P. (2010, July). Monte Carlo method for assessing multilevel Mediation: An interactive tool for creating confidence intervals for indirect effects in 1-1-1 multilevel models [Computer software]. Retrieved from http://quantpsy.org/. Preacher, K. J., \& Selig, J. P. (2012). Advantages of Monte Carlo confidence intervals for indirect effects. Communication Methods and Measures, 6(2), 77-98. http://dx.doi.org/10.1080/19312458.2012.679848

Raudenbush, S. W., \& Bryk, A. S. (2002). Hierarchical linear models. Newbury Park, CA: Sage. 
Reis, H. T., \& Gable, S. L. (2000). Event-sampling and other methods for studying everyday experience. In T. H. Reis \& M. C. Judd (Eds.), Handbook of research methods in social and personality psychology (pp. 190-222). New York, NY: Cambridge University Press.

Rich, B. L., Lepine, J. A., \& Crawford, E. R. (2010). Job engagement: Antecedents and effects on job performance. Academy of Management Journal, 53(3), 617-635. http://dx.doi.org/10.5465/AMJ.2010.51468988

Rioux, S. M., \& Penner, L. A. (2001). The causes of organizational citizenship behavior: A motivational analysis. Journal of Applied Psychology, 86, 1306-1314. http://dx.doi.org/10.1037//0021-9010.86.6.1306

Rodríguez-Muñoz, A., Sanz-Vergel, A. I., Demerouti, E., \& Bakker, A. B. (2014). Engaged at work and happy at home: A spillover-crossover model. Journal of Happiness Studies, 15, 271-283. http://dx.doi.org/10.1007/s10902-013-9421-3

Rothbard, N. P. (2001). Enriching or depleting? The dynamics of engagement in work and family roles. Administrative Science Quarterly, 46(4), 655-684. http://dx.doi.org/10.2307/3094827

Ryan, R. M., \& Connell, J. P. (1989). Perceived locus of causality and internalization: Examining reasons for acting in two domains. Journal of Personality and Social Psychology, 57, 749-761. http://dx.doi.org/10.1037/0022-3514.57.5.749

Ryan, R. M., \& Deci, E. L. (2000). Self-determination theory and the facilitation of intrinsic motivation, social development, and well-being. American Psychologist, 55, 68-78. http://dx.doi.org/10.1037//0003-066x.55.1.68

Salanova, M., \& Schaufeli, W. B. (2008). A cross-national study of work engagement as a mediator between job resources and proactive behaviour. The International Journal of 
Human Resource Management, 19(1), 116-131.

http://dx.doi.org/10.1080/09585190701763982

Schaufeli, W. B., \& Bakker, A. B. (2010). Defining and measuring work engagement:

Bringing clarity to the concept. In A. B. Bakker \& M.P. Leiter (Eds.), Work

engagement: A handbook of essential theory and research (pp. 10-24). New York:

Psychology Press.

Schaufeli, W. B., Bakker, A. B., \& Salanova, M. (2006). The measurement of work engagement with a short questionnaire: A cross-national study. Educational and Psychological Measurement, 66, 701-716.

http://dx.doi.org/10.1177/0013164405282471

Schaufeli, W. B., Salanova, M., González-Romá, V., \& Bakker, A. B. (2002). The measurement of engagement and burnout: A two sample confirmatory factor analytic approach. Journal of Happiness Studies, 3, 71-92.

http://dx.doi.org/10.1023/a:1015630930326

Siu, O. L., Lu, J. F., Brough, P., Lu, C. Q., Bakker, A. B., Kalliath, T., O’Driscoll, M., Phillips, D. R., Chen, W. Q., Lo, D., Sit, C., \& Shi, K. (2010). Role resources and work-family enrichment: The role of work engagement. Journal of Vocational Behavior, 77, 470-480. http://dx.doi.org/10.1016/j.jvb.2010.06.007

Sonnentag, S. (2003). Recovery, work engagement, and proactive behavior: a new look at the interface between nonwork and work. Journal of Applied Psychology, 88(3), 518-528. http://psycnet.apa.org/doi/10.1037/0021-9010.88.3.518

Sonnentag, S. (2011). Research on work engagement is well and alive. European Journal of Work and Organizational Psychology, 20, 29-38. http://dx.doi.org/10.1080/1359432x.2010.510639 
Sonnentag, S., \& Bayer, U. V. (2005). Switching off mentally: predictors and consequences of psychological detachment from work during off-job time. Journal of Occupational Health Psychology, 10(4), 393-414. http://psycnet.apa.org/doi/10.1037/10768998.10.4.393

Sonnentag, S., \& Fritz, C. (2015). Recovery from job stress: The stressor-detachment model as an integrative framework. Journal of Organizational Behavior, 36(S1), S72-S103. http://dx.doi.org/10.1002/job.1924

Sonnentag, S., Mojza, E. J., Demerouti, E., \& Bakker, A. B. (2012). Reciprocal relations between recovery and work engagement: the moderating role of job stressors. Journal of Applied Psychology, 97(4), 842-853. http://psycnet.apa.org/doi/10.1037/a0028292

ten Brummelhuis, L. L., \& Bakker, A. B. (2012). A resource perspective on the work-home interface: The work-home resources model. American Psychologist, 67, 545-556. http://dx.doi.org/10.1037/a0027974

Voydanoff, P. (2005). Consequences of boundary-spanning demands and resources for workto-family conflict and perceived stress. Journal of Occupational Health Psychology, 10, 491-503. http://dx.doi.org/10.1037/1076-8998.10.4.491

Wang, M., Liu, S., Liao, H., Gong, Y., Kammeyer-Mueller, J., \& Shi, J. (2013). Can’t get it out of my mind: Employee rumination after customer mistreatment and negative mood in the next morning. Journal of Applied Psychology, 98, 989-1004. http://dx.doi.org/10.1037/a0033656

Watson, D., \& Clark, L. A. (1994). The PANAS-X: Manual for the Positive and Negative Affect Schedule-Expanded Form. Cedar Rapids: The University of Iowa.

Wayne, J. H., Grzywacz, J. G., Carlson, D. S., \& Kacmar, K. M. (2007). Work-family facilitation: A theoretical explanation and model of primary antecedents and 
consequences. Human Resource Management Review, 17, 63-76.

http://dx.doi.org/10.1016/j.hrmr.2007.01.002

Xanthopoulou, D., Bakker, A. B., Demerouti, E., \& Schaufeli, W. B. (2009a). Reciprocal relationships between job resources, personal resources, and work engagement. Journal of Vocational Behavior, 74, 235-244. http://dx.doi.org/10.1016/j.jvb.2008.11.003

Xanthopoulou, D., Bakker, A. B., Demerouti, E., \& Schaufeli, W. B. (2009b). Work engagement and financial returns: A diary study on the role of job and personal resources. Journal of Occupational and Organizational Psychology, 82, 183-200. http://dx.doi.org/10.1348/096317908X285633 
Table 1. Percentage of Within-Individual Variance among Daily Variables

\begin{tabular}{lccc}
\hline \multicolumn{1}{c}{ Daily Variables } & $\begin{array}{c}\text { Within- } \\
\text { individual } \\
\text { Variance } \\
\left(\mathrm{e}^{2}\right)\end{array}$ & $\begin{array}{c}\text { Between- } \\
\text { individual } \\
\text { Variance } \\
\left(\mathrm{r}^{2}\right)\end{array}$ & $\begin{array}{c}\% \text { of } \\
\text { Within- } \\
\text { individual } \\
\text { Variance }\end{array}$ \\
\hline State Positive Affect (evening) & 0.39 & 0.40 & $49 \%$ \\
State Negative Affect (evening) & 0.26 & 0.42 & $38 \%$ \\
Daily Work Engagement (afternoon)* & 0.25 & 0.50 & $33 \%$ \\
Daily Work-Family Interpersonal Capitalization & 0.84 & 1.01 & $45 \%$ \\
(evening) & 0.29 & 0.32 & $48 \%$ \\
Daily Family Satisfaction (evening) & 0.29 & 0.72 & $29 \%$ \\
Daily Work-Family Balance (evening) & 0.43 & 0.60 & $42 \%$ \\
Spouse's Daily Family Satisfaction (evening) & & & \\
\hline
\end{tabular}

Notes: The percentage of within-individual variance was calculated as $\mathrm{e}^{2} /\left(\mathrm{e}^{2}+\mathrm{r}^{2}\right)$. $* \mathrm{We}$ conducted a literature search for studies that measured daily work engagement using experience-sampling methodology to ascertain how the variability in work engagement observed in our study compares to other findings. Among the 20 studies that had reported the percentage of total variance caused by within-individual variation (from a total of 30 experience-sampling studies on engagement that we found) this percentage varied from $26 \%$ to $74 \%$, with a mean of $44 \%(S D=13 \%)$, and in half the studies this percentage was below $40 \%$. Thus, although the percentage of total variance cause by within-individual variation is slightly lower in our study, it is within the range observed in other research. 
Table 2. Descriptive Statistics and Correlations among Study Variables

\begin{tabular}{|c|c|c|c|c|c|c|c|c|c|c|c|}
\hline \multirow{2}{*}{ Variables } & \multirow{2}{*}{ Mean } & \multirow{2}{*}{$S D w$} & \multirow{2}{*}{$S D b$} & \multicolumn{8}{|c|}{ Correlations } \\
\hline & & & & 1 & 2 & 3 & 4 & 5 & 6 & 7 & 8 \\
\hline $\begin{array}{l}\text { 1. State Positive Affect } \\
\text { (evening) }\end{array}$ & 4.21 & .63 & .64 & $(.80)$ & -.07 & $.42 * *$ & $.32 * *$ & $.20^{*}$ & $.47 * *$ & .16 & $.18^{*}$ \\
\hline $\begin{array}{l}\text { 2. State Negative Affect } \\
\text { (evening) }\end{array}$ & 2.40 & .51 & .65 & $-.24 * *$ & $(.83)$ & -.12 & -.02 & $-.32 * *$ & $-.19 *$ & -.08 & -0.08 \\
\hline $\begin{array}{l}\text { 3. Daily Work } \\
\text { Engagement (afternoon) }\end{array}$ & 4.93 & .50 & .71 & .05 & $-.12 * *$ & $(.90)$ & $.36^{* *}$ & $.37 * *$ & $.58 * *$ & $.21^{*}$ & $.52 * *$ \\
\hline $\begin{array}{l}\text { 4. Daily Work-Family } \\
\text { Interpersonal } \\
\text { Capitalization (evening) }\end{array}$ & 5.19 & .92 & 1.01 & $.15^{* *}$ & $-.16^{* *}$ & $.09 * *$ & $(.93)$ & $.28 * *$ & $.56^{* *}$ & .17 & 0.13 \\
\hline $\begin{array}{l}\text { 5. Daily Family } \\
\text { Satisfaction (evening) }\end{array}$ & 6.03 & .54 & .56 & $.08 * *$ & $-.11 * *$ & .05 & $.20 * *$ & $(.74)$ & $.46^{* *}$ & $.36 * *$ & 0.09 \\
\hline $\begin{array}{l}\text { 6. Daily Work-Family } \\
\text { Balance (evening) }\end{array}$ & 5.02 & .54 & .85 & $.16^{* *}$ & $-.16 * *$ & $.11 * *$ & $.20 * *$ & $.26 * *$ & $(.94)$ & $.29 * *$ & $.23 * *$ \\
\hline $\begin{array}{l}\text { 7. Spouse's Daily Family } \\
\text { Satisfaction (evening) }\end{array}$ & 5.95 & .66 & .78 & .03 & -.01 & -.02 & .03 & $.11 * *$ & .04 & $(.81)$ & 0.07 \\
\hline $\begin{array}{l}\text { 8. Intrinsic Motivation } \\
\text { (between-person level) }\end{array}$ & 5.25 & - & 1.18 & - & - & - & - & - & - & - & $(.89)$ \\
\hline
\end{tabular}

Notes: Correlations below the diagonal represent within-individual correlations $(N=1250)$. Correlations above the diagonal represent between-individual correlations $(N=125) . S D w$ and $S D b$ are standard deviations computed within and between individuals, respectively. Coefficient alpha estimates of reliability are in parentheses on the diagonal. For the within-individual variables, their reliabilities were the mean alphas across 10 days of observation.

$* p<.05, * * p<.01$ 
Table 3. Multilevel Path Analysis Results for Testing Hypotheses 1-3

\begin{tabular}{|c|c|c|c|c|c|c|}
\hline \multirow[t]{2}{*}{ Level-1 Predictors } & \multicolumn{2}{|c|}{$\begin{array}{l}\text { Daily Family } \\
\text { Satisfaction } \\
\text { (H1) }\end{array}$} & \multicolumn{2}{|c|}{$\begin{array}{l}\text { Daily Work-Family } \\
\text { Balance (H2) }\end{array}$} & \multicolumn{2}{|c|}{$\begin{array}{c}\text { Work-Family } \\
\text { Interpersonal } \\
\text { Capitalization } \\
\text { (H3) }\end{array}$} \\
\hline & Estimate & $S E$ & Estimate & $S E$ & $\begin{array}{c}\text { Estimat } \\
\mathrm{e}\end{array}$ & $S E$ \\
\hline Intercept & $6.04 * *$ & 0.05 & $5.02 * *$ & 0.08 & $5.18 * *$ & 0.09 \\
\hline \multicolumn{7}{|l|}{ Control Variables } \\
\hline Positive Affect at Home & 0.06 & 0.04 & $0.10 * *$ & 0.04 & $0.17 * *$ & 0.06 \\
\hline Negative Affect at Home & $-0.10^{*}$ & 0.04 & $-0.12 *$ & 0.05 & $-0.23 * *$ & 0.07 \\
\hline \multicolumn{7}{|l|}{ Predictor } \\
\hline Daily Work Engagement & 0.03 & 0.04 & $0.10 *$ & 0.04 & $0.15^{*}$ & 0.07 \\
\hline Level-1 Residual Variance & $0.28 * *$ & 0.04 & $0.26^{* *}$ & 0.03 & $0.76^{* *}$ & 0.10 \\
\hline
\end{tabular}

Notes: The above estimates represent unstandardized path coefficients. $\mathrm{H} 1$ and $\mathrm{H} 2$ were estimated simultaneously in the same path-analytical model. H3 was estimated in a separate path-analytical model, yet the results were essentially the same when all three family outcomes were included in the same model. In both models, all hypothesized effects were specified as random slopes, while the effects of control variables were specified as fixed slopes.

$* p<.05, * * p<.01$. 


\section{Table 4. Multilevel Path Analysis Results for Testing Hypotheses 4 and 5}

\begin{tabular}{|c|c|c|c|c|c|c|}
\hline \multirow[t]{2}{*}{ Level-1 Predictors } & \multicolumn{2}{|c|}{$\begin{array}{c}\text { Work-family } \\
\text { Interpersonal } \\
\text { Capitalization }\end{array}$} & \multicolumn{2}{|c|}{$\begin{array}{l}\text { Daily Family } \\
\text { Satisfaction }\end{array}$} & \multicolumn{2}{|c|}{$\begin{array}{l}\text { Daily Work- } \\
\text { Family Balance }\end{array}$} \\
\hline & Estimate & $S E$ & Estimate & $S E$ & Estimate & $S E$ \\
\hline \multicolumn{7}{|l|}{ Control Variables } \\
\hline Positive Affect at Home & $0.17 * *$ & 0.06 & 0.03 & 0.03 & $0.08^{*}$ & 0.03 \\
\hline Negative Affect at Home & $-0.22 * *$ & 0.07 & $-0.07 *$ & 0.03 & $-0.11 *$ & 0.05 \\
\hline \multicolumn{7}{|l|}{ Predictors } \\
\hline Daily Work Engagement & $0.15^{*}$ & 0.08 & -0.02 & 0.04 & 0.06 & 0.04 \\
\hline $\begin{array}{l}\text { Work-Family Interpersonal } \\
\text { Capitalization }\end{array}$ & & & $0.18^{* *}$ & 0.04 & $0.12 * *$ & 0.02 \\
\hline Level-1 Residual Variance & $0.68^{* *}$ & 0.09 & $0.22 * *$ & 0.04 & $0.25^{* *}$ & 0.03 \\
\hline
\end{tabular}

Notes: The above estimates represent unstandardized path coefficients. $\mathrm{H} 4$ and $\mathrm{H} 5$ were estimated simultaneously in the same path-analytical model. All hypothesized effects were specified as random slopes, while the effects of control variables were specified as fixed slopes.

$* p<.05, * * p<.01$. 


\section{Table 5. Testing the Cross-Level Moderating Effect of Intrinsic Motivation}

\begin{tabular}{|c|c|c|}
\hline & \multicolumn{2}{|c|}{$\begin{array}{l}\text { Work-Family Interpersonal } \\
\text { Capitalization (H6) }\end{array}$} \\
\hline & Estimate & $S E$ \\
\hline \multicolumn{3}{|l|}{ Level 1: } \\
\hline Intercept & $5.19 * *$ & 0.09 \\
\hline \multicolumn{3}{|l|}{ Control Variables } \\
\hline Positive Affect at Home & $0.17 * *$ & 0.06 \\
\hline Negative Affect at Home & $-0.22 * *$ & 0.07 \\
\hline \multicolumn{3}{|l|}{ Predictor } \\
\hline Daily Work Engagement & $0.17 *$ & 0.07 \\
\hline \multicolumn{3}{|c|}{ Level 2: Moderating Effect of Intrinsic Motivation } \\
\hline On the Intercept & 0.12 & 0.07 \\
\hline On the Random Slope & $0.11 *$ & 0.05 \\
\hline
\end{tabular}

Notes: Hypothesized within-individual effects were specified as random slopes, while the effects of control variables were specified as fixed slopes.

$* p<.05, * * p<.01$. 


\section{Figure 1. Conceptual Model and the Results of Multi-Level Path Analysis}

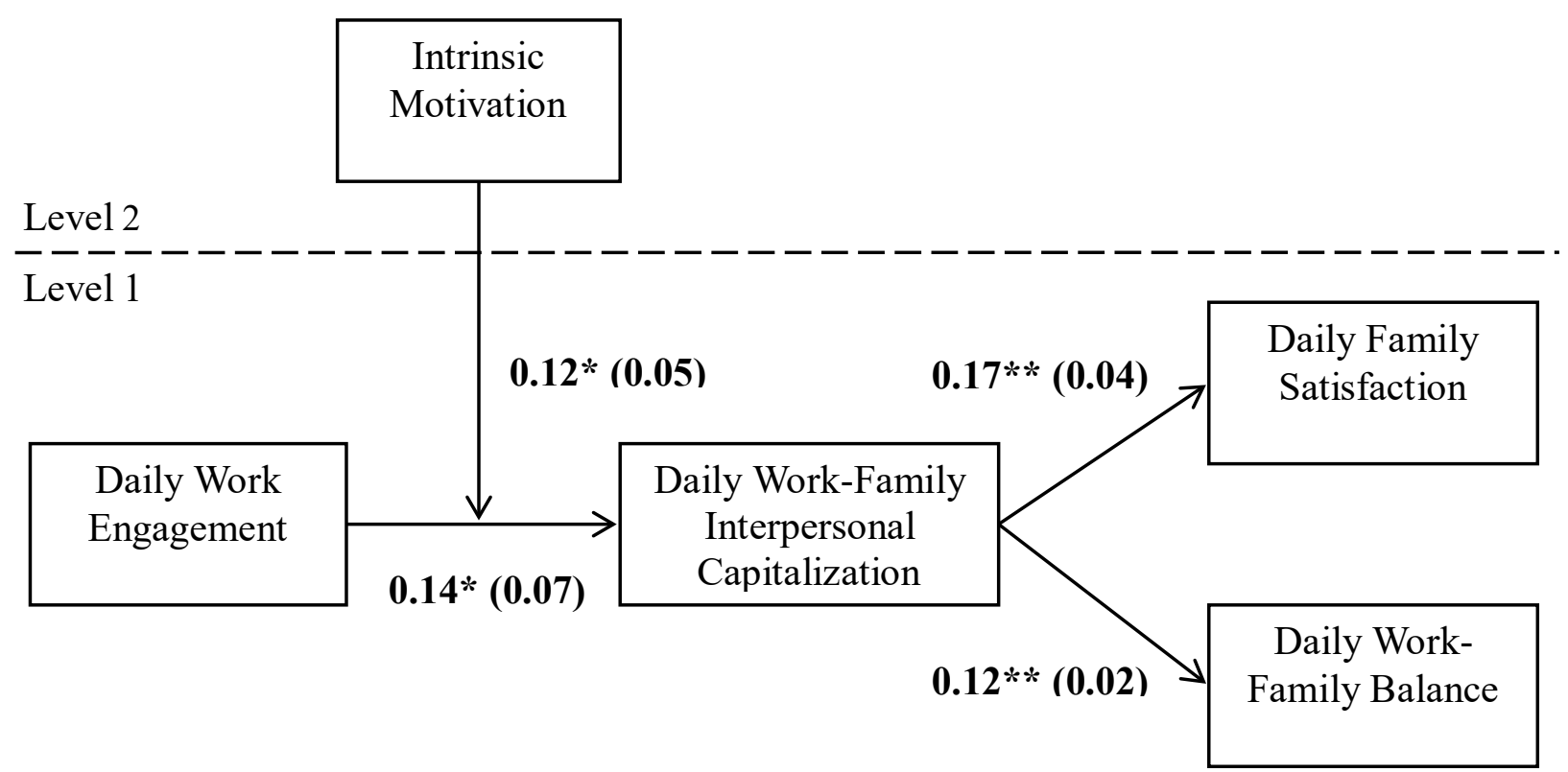

Notes: Path coefficients are unstandardized estimates (standard errors are in parentheses). All paths were estimated simultaneously in the same path-analytical model. All hypothesized effects at Level 1 (including the direct effects of daily work engagement on daily family satisfaction and daily work-family balance) were specified as random slopes and thus were freely estimated, and were allowed to covary with each other. For parsimony, we do not include the effects of control variables (i.e., positive affect and negative affect at home) on the endogenous variables, which were specified as fixed slopes in the model.

$* p<.05, * * p<.01$. 
Figure 2. Cross-Level Moderating Effect of Intrinsic Motivation on the Within-Individual Relationship between Work Engagement and Work-Family Interpersonal Capitalization

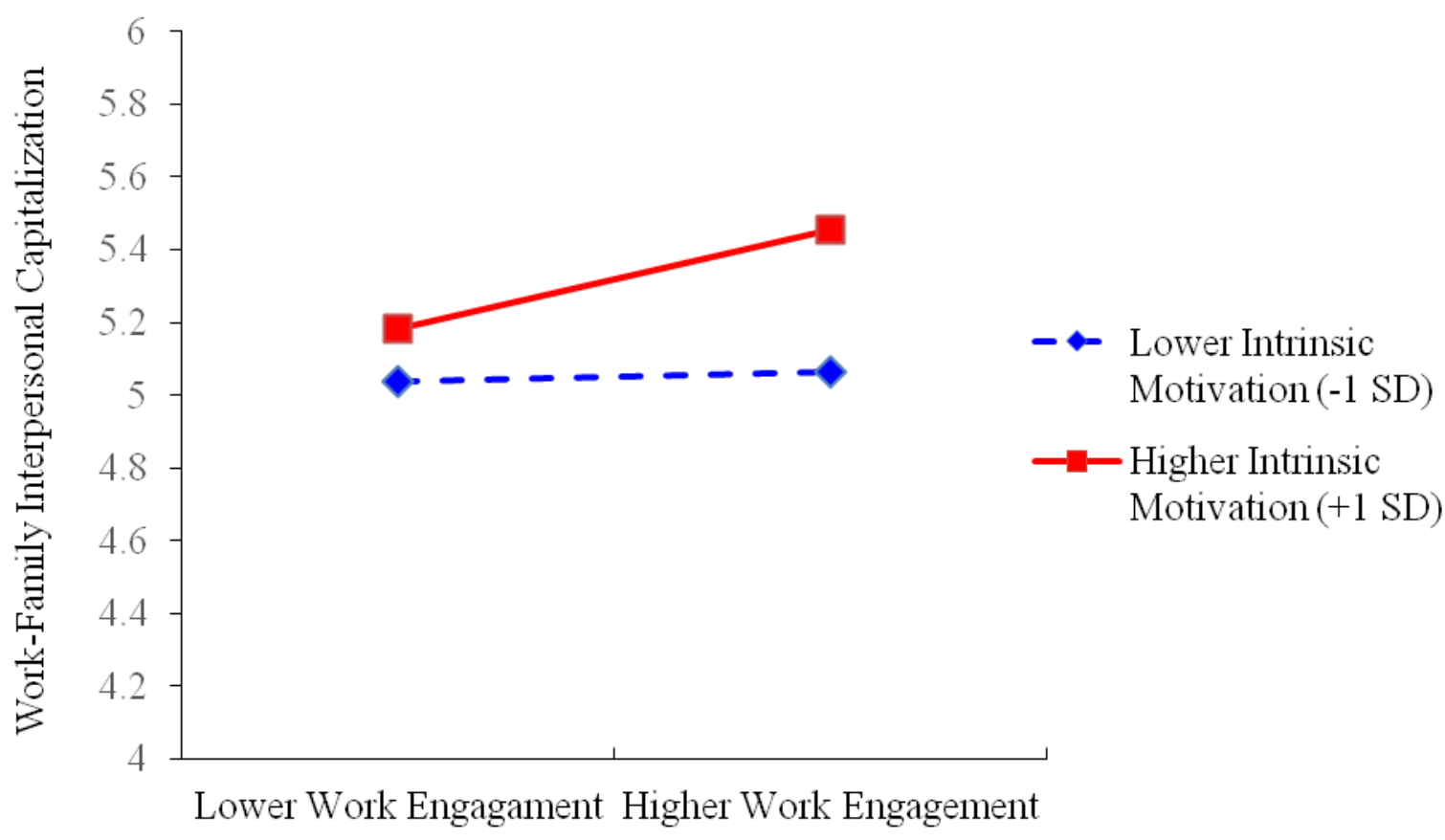

